\title{
Mapping of Bacterial Blight Resistance Gene Xa11 on Rice Chromosome 3
}

\author{
Takahiro GOTO, Tadayuki MATSUMOTO, Naruto FURUYA, \\ Kenichi TSUCHIYA and Atsushi YOSHIMURA*
}

Faculty of Agriculture, Kyushu University (Fukuoka, Fukuoka 812-8581, Japan)

\begin{abstract}
The bacterial blight (BB) resistance gene Xa11 confers resistance in rice to Japanese races IB, II, IIIA, and V of the BB pathogen Xanthomonas oryzae pv. oryzae (Xoo). Here, we report the mapping of Xa11 by using randomly amplified polymorphic DNA (RAPD), cleaved amplified polymorphic sequence (CAPS), and simple sequence repeat (SSR) markers. To detect DNA markers linked to Xa11, we used an Xa11 near-isogenic line, IR-BB11 (in genetic background of IR24), and the susceptible cultivar IR24. The RAPD fragment L19 ${ }_{1200}$, putatively linked to Xa11, was identified. Cloning and sequencing of the L19 $9_{1200}$ product indicated that it was held in the Rice Genome Program database as accession number AC097277, and that it occurs on chromosome 3. On the basis of the sequences of L19 $_{1200}$ and the flanking genomic region, we designed CAPS marker KUX11 and selected two SSR markers, RM347 and RM1350, for mapping Xa11. To confirm the putative linkage among Xa11 and the three markers, we conducted linkage analysis using the $\mathrm{F}_{2}$ population of a cross between IR24 and IR-BB11. Each $\mathrm{F}_{2}$ plant was inoculated with strain T7156 (race IB) and genotyped with KUX11, RM347, and RM1350. Segregation in the $\mathrm{F}_{2}$ located Xa11 between the loci of RM347 (2.0 cM) and KUX11 $(1.0 \mathrm{cM})$ on the long arm of chromosome 3. These results should be useful for the markerassisted selection of Xa11 in breeding programs and for cloning Xa11 by map-based cloning.
\end{abstract}

Discipline: Plant Breeding

Additional key words: cleaved amplified polymorphic sequence (CAPS), linkage, randomly amplified polymorphic DNA (RAPD), simple sequence repeat (SSR), Xanthomonas oryzae pv. oryzae.

\section{Introduction}

Bacterial blight (BB) caused by Xanthomonas oryzae pv. oryzae (Xoo) is one of the most serious diseases in rice (Oryza sativa L.) worldwide. Breeding and deployment of resistant cultivars carrying major resistance $(R)$ genes have given the most effective approach to controlling BB. More than 30 major genes which confer resistance to various Xoo strains have been identified and are used as the main sources for genetic improvement of rice for resistance to Xoo in Asia.

Genetic and physical mapping of these $R$-genes not only permits marker-assisted breeding in rice, but also facilitates isolation and characterization of these genes at the molecular level. So far, $17 \mathrm{BB} R$-genes have been mapped on rice chromosomes and used for transferring and pyramiding in marker assisted selection (MAS) ${ }^{19,26}$.
In particular, six R-genes, Xa1, xa5, xa13, Xa21, Xa26, and $X a 27$, were cloned by map-based cloning $3,6,9,20,22,27$. However, Xa11, xa15, Xa16, Xa17, Xa18, xa19, xa20, xa24, and $x a 28$ have not been mapped yet.

Ogawa and Yamamoto ${ }^{14}$ identified the BB resistance gene Xa11, and Ogawa et al. ${ }^{17}$ found it in the cultivars or lines IR8, Elwee, RP9-3, Peta, and IR944-102-3-2. Xa11 confers specific resistance to strains T7156, T7147, T7133, and H75304 (Japanese Xoo races IB, II, IIIA, and $\mathrm{V}$, respectively) ${ }^{13,17}$. IR-BB11, a near isogenic line (NIL) carrying Xa11, was developed at the International Rice Research Institute (IRRI) and the former Tropical Agriculture Research Center (TARC), now the Japan International Research Center for Agricultural Sciences (JIRCAS) $)^{15,16}$. In this study, we report the identification of molecular markers closely linked to Xa11, and the mapping of Xa11 in an IR24 $\times$ IR-BB11 cross. 


\section{Materials and methods}

\section{Plant materials and disease evaluation}

We used a near-isogenic line, IR-BB11, carrying Xa11 in the genetic background of the susceptible cultivar IR24 for RAPD analysis and as a donor of Xa11. We used IR24 as a control cultivar for RAPD analysis and as a parent for $\mathrm{F}_{2}$ analysis. IR-BB11 showed resistance to Japanese races IB, II, IIIA and V (Fig. 1a), as described previously ${ }^{17}$. Two $\mathrm{F}_{2}$ populations derived from a cross between IR24 and IR-BB11 were used for RAPD analysis of markers putatively linked to Xa11 and for genetic analysis of Xa11. The first population was sown on 1993 May 15, and the second on 2006 May 24. The plants were transplanted 30 days after sowing into concrete beds at Kyushu University, and the parents and $\mathrm{F}_{2}$ plants showed uniform growth. The soil was fertilized with N-P-K at 9-6-6 g/m² before transplanting, and additional nitrogen was applied at $3 \mathrm{~g} / \mathrm{m}^{2}$ before inoculation.

Plants were inoculated with strain T7156 (Japanese race IB). The strain was cultured on potato semi-synthetic agar (PSA) medium at $30^{\circ} \mathrm{C}$ for 3 days $^{24}$. Bacteria were suspended in sterile distilled water at a concentration of approximately $10^{8-9} \mathrm{cfu} / \mathrm{mL}$ as inoculum. At booting stage, five of the uppermost fully expanded leaves of each plant were inoculated by the leaf-clipping method ${ }^{10}$. Plants were inoculated on 2006 August 4, and reactions of individual $F_{2}$ plants were evaluated two or three times during 14-21 days after inoculation. The disease reac- (a)

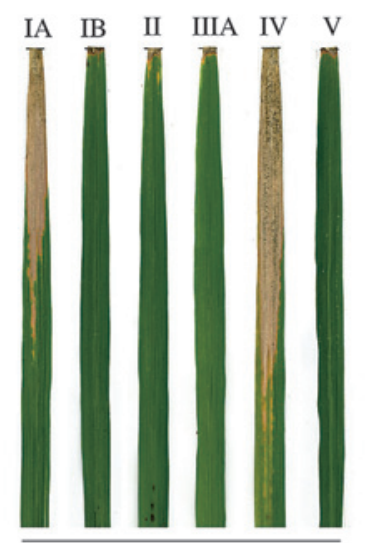

IR-BB11 (b)

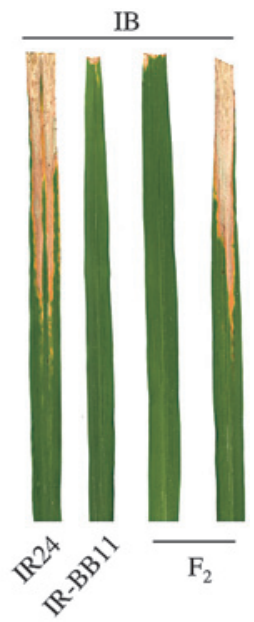

Fig. 1. Pathogenic reaction of Xanthomonas oryzae pv. oryzae on rice

(a) IR-BB11 inoculated with six Xoo strains: T7174 (race IA), T7156 (IB), T7147 (II), T7133 (IIIA), H75373 (IV), H75304 (V). (b) IR24, IR-BB11, and $\mathrm{F}_{2} \mathrm{~s}$ derived from IR24 $\times$ IR-BB11 inoculated with Xoo strain T7156. tion was categorized by eye as resistant (R) or susceptible (S) according to the degree of development. For example, a lesion that stopped at the cut margin was categorized as $\mathrm{R}$, but a lesion that expanded along a vein was categorized as $\mathrm{S}$.

\section{PCR conditions for RAPD, CAPS, and SSR analy- sis}

For RAPD analysis, we used 500 ten-base arbitrary primers (RAPD kits; Operon Biotechnologies Inc., Tokyo, Japan) to screen for polymorphisms between IR24 and IR-BB11. DNAs were extracted from fresh leaves according to Dellaporta et al. ${ }^{4}$ Amplification reactions were performed in $25-\mu \mathrm{L}$ reaction volumes containing $50 \mathrm{mM}$ $\mathrm{KCl}, 10 \mathrm{mM}$ Tris $\cdot \mathrm{HCl}$ (pH 9.0), $2.0 \mathrm{mM} \mathrm{MgCl}_{2}, 0.2 \mathrm{mM}$ dNTPs, $1 \mathrm{U}$ Taq polymerase, $0.4 \mu \mathrm{M}$ primers, and $25 \mathrm{ng}$ genomic DNA in a PCR System-9700 (Applied Biosystems, Foster City, CA, USA). The PCR program was one cycle at $94^{\circ} \mathrm{C}$ for $4 \mathrm{~min} ; 40$ cycles of $1 \mathrm{~min}$ at $94^{\circ} \mathrm{C}, 1 \mathrm{~min}$ at $35^{\circ} \mathrm{C}$, and $1 \mathrm{~min}$ at $72^{\circ} \mathrm{C}$; and a final extension step at $75^{\circ} \mathrm{C}$ for $5 \mathrm{~min}$ before cooling to $4^{\circ} \mathrm{C}$. Amplified products were resolved by electrophoresis at $35 \mathrm{~V}$ for $5 \mathrm{~h}$ in $1.5 \%$ agarose gels. The gels were stained with ethidium bromide, and the DNA fragments were visualized with UV light and photographed.

The CAPS marker KUX11 (F:5'-GTGATTCCGCGAAAGTGAAT-3', R: 5'-AGTGTGAGGATGGGAAGCAC-3') was designed and used to genotype the $F_{2}$ population. The PCR reaction mixture for the PCR-based markers contained 10-20 ng template DNA, $0.3 \mu \mathrm{M}$ primers, 0.2 mM dNTPs, 50 mM KCl, 10mM Tris $\cdot \mathrm{HCl}$ (pH 9.0), 2 mM $\mathrm{MgCl}_{2}$, and $1 \mathrm{U}$ Taq DNA polymerase in a final volume of $25 \mu \mathrm{L}$. The DNA was amplified in 30 cycles of $94^{\circ} \mathrm{C}$ for $1 \mathrm{~min}, 60^{\circ} \mathrm{C}$ for $1 \mathrm{~min}$, and $72^{\circ} \mathrm{C}$ for $2 \mathrm{~min}$. The amplified DNA was digested with restriction enzyme (SnaBI) and analyzed by electrophoresis in 4\% agarose gels.

The SSR markers RM347 and RM1350 were also used for genotyping. The PCR mixture contained 10-20 ng template DNA, $0.2 \mu \mathrm{M}$ primers, $1.5 \mathrm{mM} \mathrm{MgCl}_{2}, 0.2$ mM dNTPs, $50 \mathrm{mM} \mathrm{KCl,} \mathrm{10mM} \mathrm{Tris \cdot HCl} \mathrm{(pH} \mathrm{9.0),} \mathrm{and} 1$ U Taq DNA polymerase in a total volume of $15 \mu \mathrm{L}$. The PCR program was one denaturation step of $5 \mathrm{~min}$ at $94^{\circ} \mathrm{C}$, followed by 35 cycles of $30 \mathrm{~s}$ at $94^{\circ} \mathrm{C}, 30 \mathrm{~s}$ at $55^{\circ} \mathrm{C}$, and 30 $\mathrm{s}$ at $72^{\circ} \mathrm{C}$. The PCR products were resolved by electrophoresis at $200 \mathrm{~V}$ for $50 \mathrm{~min}$ in $4 \%$ agarose gels containing ethidium bromide in $0.5 \times$ TBE buffer.

\section{DNA sequencing}

Amplified products of the correct size were recovered from agarose gel with a Qiaquick gel extraction kit (Qiagen GmbH, Hilden, Germany). Recovered DNA fragments were cloned in the pGEM-T vector system 
(Promega GmbH, Mannheim, Germany), following the manufacturer's instructions. A BigDye Terminator Cycle Sequencing v3.1 kit (Applied Biosystems, Foster City, CA, USA) were used for sequencing. DNA sequence similarity analysis was performed by using the BLAST algorithm (http://www.ncbi.nlm.nih.gov/).

\section{Linkage analysis}

For linkage analysis, CAPS and SSR genotypes of each plant were scored as codominant characters, and the disease reaction was scored as dominant or recessive. Recombination values were estimated by using the maximum likelihood equation, and the recombination values were converted into genetic map distance (cM) by using Kosambi’s mapping function ${ }^{11}$.

\section{Results}

To detect RAPD markers putatively linked to Xa11, we screened IR-BB11 and IR24 using 500 arbitrary primers. Although most of the amplified fragments were identical in both lines, one polymorphic fragment was identified: primer L19 (5'-GAGTGGTGAC-3') yielded a 1200-bp fragment from IR-BB11 but not from IR24 (Fig. 2a). We named this fragment L19 ${ }_{1200}$. L19 ${ }_{1200}$ was cloned into the pGEM-T vector and sequenced. Polymorphism between IR-BB11 and IR24 was found at the SnaBI restriction site, so we designed the CAPS marker KUX11 (F: 5'-GTGATTCCGCGAAAGTGAAT-3', R: 5'-AGTGTGAGGATGGGAAGCAC-3') to amplify DNA containing that site. KUX11 amplified a 900-bp fragment from both IR24 and IR-BB11. Digestion of the fragment with SnaBI produced two fragments ( 650 bp and $\sim 250$ bp) from IR24 and one fragment (no digestion) from IR-BB11 (Fig. 2b). We searched rice genome sequences in the NCBI database (http://www.ncbi.nlm.nih.gov/) with the L19 ${ }_{1200}$ sequence as a query. The sequence was present in RGP contig AC097277 from chromosome 3. We then screened 32 SSR markers in the genomic region flanking AC097277 to detect polymorphisms between IR-BB11 and IR24. Two SSR markers-RM347 and RM1350_showed clear polymorphism.

To confirm the putative linkage among the loci of Xa11, KUX11, RM347, and RM1350 on chromosome 3, we conducted linkage analysis. First we assessed disease reactions of $189 \mathrm{~F}_{2}$ plants derived from IR24 × IR-BB11 to Хоo. The $\mathrm{F}_{2}$ plants were clearly classified either as resistant or as susceptible (Fig. 1b): 138 plants were resistant and 51 were susceptible. The segregation of resistant and susceptible plants in the $F_{2}$ population fitted the 3:1 ratio $\left(\chi^{2}=0.397, P=0.529\right)$, which indicates that the resistance of IR-BB11 to T7156 is controlled by a single dominant gene, Xa11. Each plant was also genotyped with the three DNA markers and scored for codominance of the trait. The segregation of the three markers fitted the expected ratio of 1:2:1 (for RM347, $\chi^{2}=5.564, P=0.062$; for RM1650, $\chi^{2}=5.500, P=0.064$; for KUX11, $\chi^{2}=5.011, P$ $=0.082$ ), indicating their monogenic inheritance. The segregation pattern of Xa11 with the three DNA markers revealed that three DNA markers were closely linked to Xa11. The cosegregation pattern of Xa11 (resistant/susceptible) and KUX11 genotypes in $\mathrm{F}_{2}$ is shown in Fig. 2b as an example. The arrangement of the four loci was RM347-Xa11-KUX11-RM1350. Xa11 was located between RM347 and KUX11 at genetic distances of 2.0 and $1.0 \mathrm{cM}$, respectively (Fig. 3).

(a)
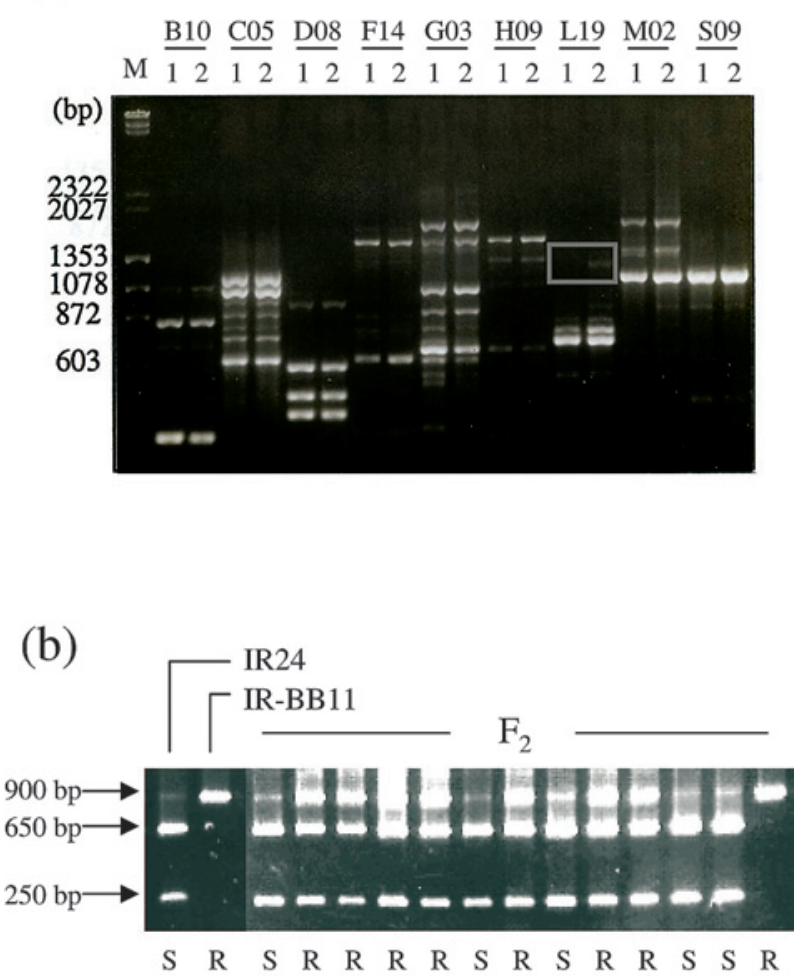

Fig. 2. Detection of polymorphisms between IR24 and IR-BB11

(a) Detection of random amplified polymorphic DNA (RAPD) by nine arbitrary primers. Amplification products were separated by electrophoresis. 1: IR24; 2: IR-BB11; M: Molecular marker. (b) Segregation of the CAPS marker KUX11 in $\mathrm{F}_{2}$ population. A 900-bp fragment was amplified from both IR24 and IR-BB11 by KUX11. After digestion of this fragment with SnaBI, two fragments ( 650 bp and $250 \mathrm{bp}$ ) from IR24 and one fragment (900 bp, no digestion) from IR-BB11 were revealed by electrophoresis in agarose gel. R: resistant; S: susceptible. 


\section{Discussion}

Ogawa and colleagues reported that IR8, a parent of IR-BB11, shares a dominant gene, Xa11, for resistance to Japanese races IB, II, IIIA, and V of $X_{0 o^{13,17}}$. However, the chromosomal location of the gene was not known. Our results reveal that Xa11 is located on chromosome 3 between DNA markers RM347 (2.0 cM) and KUX11 (1.0 $\mathrm{cM})$. These markers will provide a significant contribution to cloning and molecular characterization of Xa11.

Since RAPD fragment L19 ${ }_{1200}$ had been identified before the completion of the rice genomic sequence and the advent of SSR markers, the method we used to identify the chromosomal location of Xa11 in this study was different from the current method of identifying the location of an unmapped gene. We detected the PCR product putatively linked to Xa11 by RAPD analysis of a NIL and then identified its chromosomal location from the DNA sequence information. This method facilitated the mapping of Xa11.

A large number of disease resistance genes have been described in rice, and many have been roughly placed on genetic maps. However, no major disease $R$ genes have previously been located on chromosome 3, only some insect $R$-genes, such as bph11 and Grh4 $4^{5,8}$. Only quantitative trait loci for bacterial leaf streak, rice blast, and sheath blight resistance genes were known on chromosome $3^{2,23,29}$. Our results provide the first report of the location of a major resistance gene for BB on chromosome 3 .
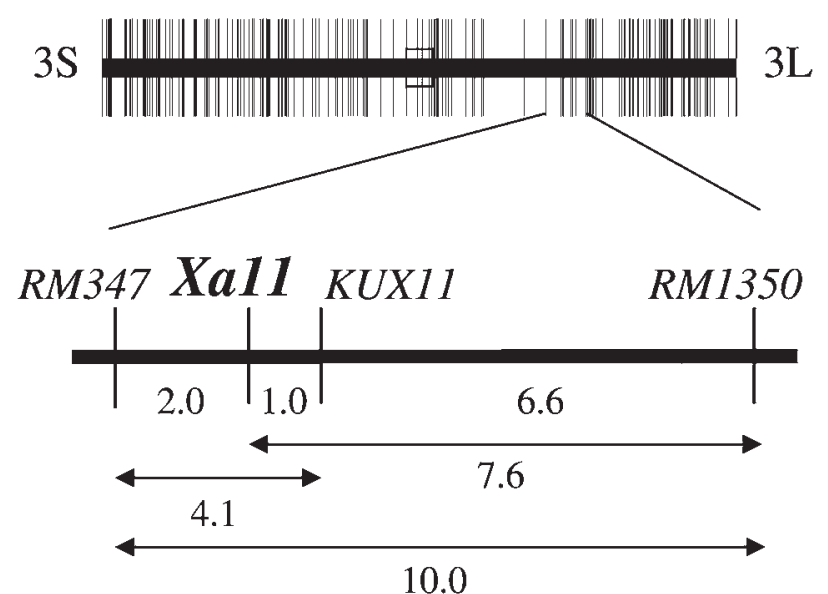

Fig. 3. Linkage map indicating the position of Xa11 on chromosome 3

Vertical bars represent SSR and CAPS markers used for the linkage analysis. Framework maps were quoted from Harushima et al.7. Numbers indicate map distances (cM).
Most dominant $R$-genes encode structurally related proteins with predicted extracellular or intracellular leucine-rich repeat (LRR) motifs. Xa21, the first cloned $R$ gene for $\mathrm{BB}$, is a member of a multigene family in rice, and encodes a receptor-like kinase protein with a predicted extracellular LRR domain, a transmembrane domain, and a cytoplasmic kinase domain ${ }^{20,21}$. Xa26 encodes a protein structurally similar to that encoded by $\mathrm{Xa21}$, but with a slightly larger LRR domain. Both genes are broad spectrum $R$-genes. Xa1 encodes a nucleotide binding site (NBS)-LRR protein ${ }^{27}$. The rice blast $R$-genes Pib, Pita, Piz-t, and Pi9 also encode NBS-LRR proteins ${ }^{1,18,25,28}$. Fewer clusters of NBS-LRR and related genes are located on chromosome 3 than on the other chromosomes ${ }^{12}$. This result is consistent with the fact that few major $R$ genes are located on chromosome 3 : most BB and rice blast resistance genes are closely associated with clusters of NBS-LRR genes. The Xa11 candidate region flanked by markers RM347 and KUX11 in Nipponbare contains nine BAC clones (AC079830, AC079889, AC133335, AC084406, AC079736, AC087412, AC087851, AC092779, and AC097277). The Rice Genome Automated Annotation System (RiceGAAS, http://ricegaas.dna.affrc.go.jp/) and Rice Annotation Project Database (RAP-DB, http:// rapdb.dna.affrc.go.jp/) predict two genes encoding putative NB-LRR proteins in AC097277. One of these genes may be an Xa11 homolog.

Information on chromosome location and molecular markers linked to Xa11 is important in breeding for BB resistance such as by gene pyramiding. Our results will support fine mapping and positional cloning of Xa11.

\section{Acknowledgments}

We thank Dr. Tsugufumi Ogawa (Faculty of Agriculture, University of Miyazaki) for providing NIL IRBB11. This work was partly supported by a Grant-in-Aid for Scientific Research (B) No. 20380007 from the Ministry of Education, Culture, Sports, Science and Technology of Japan.

\section{References}

1. Bryan, G.T. et al. (2000) A single amino acid difference distinguishes resistant and susceptible alleles of the rice blast resistance gene Pi-ta. Plant Cell, 12, 2033-2046.

2. Chen, H. et al. (2003) Comparative analyses of genomic locations and race specificities of loci for quantitative resistance to Pyricularia grisea in rice and barley. Proc. Natl. Acad. Sci. USA, 100, 2544-2549.

3. Chu, Z. et al. (2006) Promoter mutations of an essential gene for pollen development result in disease resistance in rice. Genes Dev., 20, 1250-1255. 
4. Dellaporta, S.L., Wood, J. \& Hicks, J.B. (1983) A plant DNA minipreparation: version II. Plant Mol. Biol. Report., 1, 19-21.

5. Fukuta, Y. et al. (1998) Genetic analysis of resistance to green rice leafhopper (Nephotettix cincticeps Uhler) in rice parental line, Norin-PL6, using RFLP markers. Breed. Sci., 48, 243-249.

6. Gu, K. et al. (2005) $R$ gene expression induced by a type-III effector triggers disease resistance in rice. Nature, 435, 1122-1125.

7. Harushima, Y. et al. (1998) A high-density rice genetic linkage map with 2275 markers using a single $F_{2}$ population. Genetics, 148, 479-494.

8. Hirabayashi, H. et al. (1998) Identification of brown planthopper resistance gene derived from $O$. officinalis using molecular markers in rice. Breed. Res., 48 (Suppl. 1), 82.

9. Iyer, A.S. \& McCouch, S.R. (2004) The rice bacterial blight resistance gene $x a 5$ encodes a novel form of disease resistance. Mol. Plant-Microbe Interact., 17, 1348-1354.

10. Kauffman, H.E. et al. (1973) An improved technique for evaluating resistance of rice varieties to Xanthomonas oryzae. Plant Dis. Report., 57, 537-541.

11. Kosambi, D.D. (1944) The estimation of map distances from recombination values. Ann. Eugen., 12, 172-175.

12. Monosi, B. et al. (2004) Full-genome analysis of resistance gene homologues in rice. Theor. Appl. Genet., 109, 14341447.

13. Ogawa, T. (1983) Pathogenic specialization in bacterial groups I and III of Xanthomonas campestris pv. oryzae in Japan. Ann. Phytopath. Soc. Jpn., 49, 69-72.

14. Ogawa, T. \& Yamamoto, T. (1986) Inheritance of resistance to bacterial blight in rice. In rice genetics. Proc. Intl. Rice Genet. Symp., IRRI, Manila, the Philippines, 471-480.

15. Ogawa, T. et al. (1988) Near-isogenic lines as international differentials for resistance to bacterial blight of rice. Rice Genet. Newsl., 5, 106-107.

16. Ogawa, T. et al. (1991) Breeding of near-isogenic lines of rice with single genes for resistance to bacterial blight pathogen (Xanthomonas campestris pv. oryzae). Jpn. J. Breed., 41, 523-529.

17. Ogawa, T. et al. (1991) Resistance and its inheritance to bacterial blight of IR8 rice cultivar group. Jpn. J. Breed.,
41, 211-221.

18. Qu, S. et al. (2006) The broad-spectrum blast resistance gene Pi9 encodes a nucleotide-binding site - leucine-rich repeat protein and is a member of a multigene family in rice. Genetics, 172, 1901-1914.

19. Singh, S. et al. (2001) Pyramiding three bacterial blight resistance genes (xa5, xa13 and Xa21) using marker-assisted selection into indica rice cultivar PR106. Theor. Appl. Genet., 102, 1011-1015.

20. Song, W.Y. et al. (1995) A receptor kinase-like protein encoded by the rice disease resistance gene, Xa21. Science, 270, 1804-1806.

21. Song, W.Y. et al. (1997) Evolution of the rice Xa21 disease resistance gene family. Plant Cell, 9, 1279-1287.

22. Sun, X. et al. (2004) Xa26, a gene conferring resistance to Xanthomonas oryzae pv. oryzae in rice, encodes an LRR receptor kinase-like protein. Plant J., 37, 517-527.

23. Tang, D. et al. (2000) Mapping of QTLs conferring resistance to bacterial leaf streak in rice. Theor. Appl. Genet., 101, 286-291.

24. Wakimoto, S. (1955) Studies on the multiplication of OP1 phage (Xanthomonas oryzae bacteriophage) 1. One-step growth experiment under various conditions. Sci. Bull. Fac. Agric. Kyushu Univ., 15, 151-160.

25. Wang, Z.X. et al. (1999) The Pib gene for rice blast resistance belongs to the nucleotide binding and leucine-rich repeat class of plant disease resistance genes. Plant J., 19, 55-64.

26. Yoshimura, S. et al. (1995) Tagging and combining bacterial blight resistance genes in rice using RAPD and RFLP markers. Mol. Breed., 1, 375-387.

27. Yoshimura, S. et al. (1998) Expression of Xa1, a bacterial blight resistance gene in rice, is induced by bacterial inoculation. Proc. Natl. Acad. Sci. USA, 95, 1663-1668.

28. Zhou, B. et al. (2006) The eight amino-acid differences within three leucine-rich repeats between Pi2 and Piz-t resistance proteins determine the resistance specificity to Magnaporthe grisea. Mol. Plant-Microbe Interact., 19, 1216-1228.

29. Zou, J.H. et al. (2000) Mapping quantitative trait loci controlling sheath blight resistance in two rice cultivars (Oryza sativa L.). Theor. Appl. Genet., 101, 569-573. 